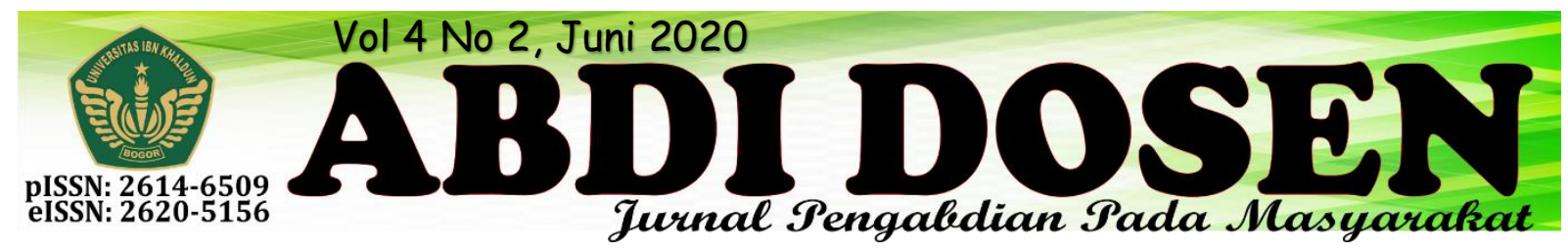

\title{
MEMBANGUN LITERASI EKONOMI DAN PENGELOLAAN SAMPAH PADA MASYARAKAT DENGAN PENDEKATAN KULTURAL
}

\author{
Hendri Maulana ${ }^{1}$, Indah Sri Redjeki ${ }^{2}$, Pri Rahmantiyo Ramadhan ${ }^{3}$ \\ endry@uika-bogor.ac.id ${ }^{1}$ \\ indahsri.redjeki@uika-bogor.ac.id $^{2}$ \\ Fakltas Ekonomi dan Bisnis Universitas Ibn Khaldun ${ }^{1}$, Fakultas Ilmu Keguruan Universitas Ibn Khaldun², \\ Mahasiswa KKN Kelompok 53\&54 Tahun $2019^{3}$
}

\begin{abstract}
ABSTRAK
Serangkaian langkah yang terpadu untuk membuka cakrawala berpikir sehingga mampu bersikap dengan tepat. literasi ekonomi akan berpengaruh juga pada bagaimana mendorong kepekaan akan bagaimana meningkatkan pola pilihan yang cerdas. Mahasiswa memperoleh pengalaman belajar melalui keterlibatan dalam masyarakat yang secara langsung menemukan, merumuskan, memecahkan dan menanggulangi permasalahan yang berada di lapangan tentang sampah rumah tangga organic dan anorganik dengan metode 3R (Reduce, Reuse, Recycle) sampah plastik yang tidak mudah terurai dangan pengelolaan yang tepat yaitu menjadi Paving Block dengan dasar sampah pelastik dilebur menjadi padat. Adapun khalayak sasaran dari pemberdayaan masyarakat yang kami lakukan yaitu warga dan anak diperkenalkan tetang menjaga kebersihan lingkungan terhadapa sampah. program-program unggulan KKN 53 dan 54 adalah Penyuluhan Penyakit DBD dan Pengelolaan Sampah.
\end{abstract}

\section{Kata Kunci: KKN, Sampah, Program, Pemberdayaan}

\section{PENDAHULUAN}

\section{A. Dasar Pemikiran}

KKN dilaksanakan oleh mahasiswa Universitas Ibn Khaldu Bogor di dalam masyarakat di luar kampus dengan maksud meningkatkan relevasi pendidikan tinggi dan menigkatkan presepsi mehasiswa tentang relevansi anatara materi kurikulan dengan realita ditengah masyarakat. Demikian Kuliah Kerja Nyata (KKN) merupakan suatu bentuk kegiatan intrakurikuler bagi mahasiswa program sarjana (S1) yang dilaksanakan dalam jangka waktu tertentu. Kelompok KKN yang terdiri dari mahasiswa lintas fakultas dan jurusan ini dimaksudkan agar dapat memberikan penyuluhan, pembelajaran dan pemberdayaan masyarakat agar membangun desa yang lebih maju.

Desa Bunar memiliki berbagai permasalahan yang membutuhkan intervensi dari pihak luar agar dapat meningkatkan kapasitas desa dan kemampuan warganya agar dapat berubah menjadi lebih baik lagi. Berbagai permasalahan tersebut di antaranya: kurangnya kesadaran akan pendidikan, rendahnya kepedulian lingkungan, kurangnya tenggang rasa dan gotong royong antar warga. Desa Bunar memiliki potensi luar biasa yang bisa dimanfaatkan untuk mengatasi berbagai permasalahan di atas. Sehingga peran dari keberadaan kelompok KKN ami di desa ini adalah 
menyalurkan potensi diri dan potensi desa sehingga permasalahan yang ada diharapkan dapat terselesaikan atau berkurang.

\section{B. Kondisi Desa Bunar}

\section{Letak Geografis}

Desa Bunar terdiri dari 5 (lima) Dusun, 14 (empat belas) Rukun Warga (RW) dan 39 (tiga puluh sembilan) Rukun Tetangga (RT). Desa Bunar adalah salah satu desa di Wilayah Kecamatan Cigudeg Kabupaten Bogor.

Bogor dengan luas wilayah 897,25 Ha. Batas Wilayah Desa Bunar adalah sebagai berikut: Sebelah Utara berbatasan dengan: Desa Mekarjaya, Sebelah Timur berbatasan dengan: Desa Cigudeg, Wargajaya Sebelah Selatan berbatasan dengan: Desa Sukamaju Sebelah Barat berbatasan dengan: Desa Pangradin, Kalong Sawah. [2]

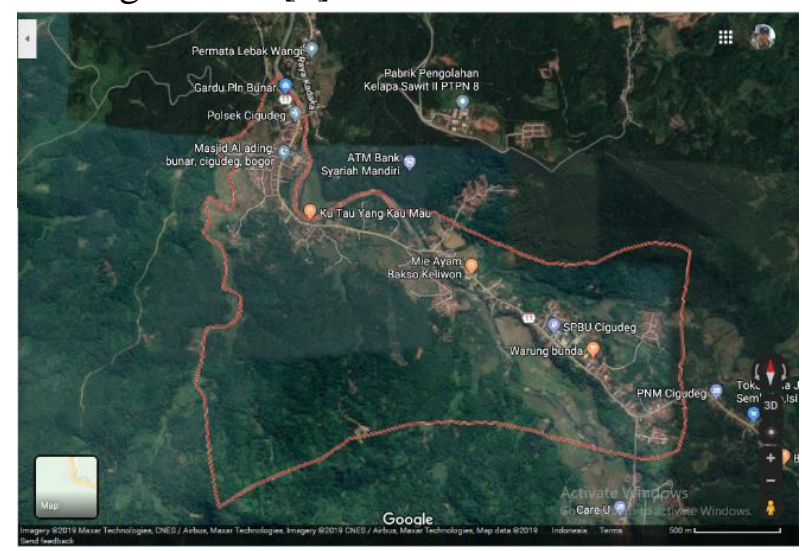

Gambar 1 Peta Desa Bunar

\section{Kondisi penduduk}

Jumlah penduduk pada Desa Bunar sebanyak 8.537 jiwa pada tahun 2015, Penduduk Desa Bunar mayoritas bermata pencaharian sebagai petani. Penduduk Desa Bunar tidak hanya bermata pencaharian sebagai petani, ada juga yang berdagang, pegawai negeri, peternak, buruh, dan lain sebagain, Menurut data yang kami terima dari aparatur desa, pada tahun 2015 jumlah penduduk yang berada di Desa Bunar, Kecamatan Cigudeg, Kabupaten Bogor berjumlah 8.537 orang yang terdiri dari 4.586 orang berjenis kelamin laki-laki dan 3.951 orang berjenis kelamin perempuan.[1]

Table 1: Jumlah Penduduk berdasarka jenis kelamin

\begin{tabular}{|l|l|l|}
\hline No & Uraian & Keterangan \\
\hline 1 & $\begin{array}{l}\text { Penduduk Laki- } \\
\text { laki }\end{array}$ & 4.586 orang \\
\hline 2 & $\begin{array}{l}\text { Penduduk } \\
\text { Perempuan }\end{array}$ & 3.951 orang \\
\hline & Total & 8.537 orang \\
\hline
\end{tabular}

Dilihatn dari struktur demografi penduduknya, Desa Bunar termasuk desa yang penduduknya terdapat jumlah masyarakat dengan usia produktif yang sangat potensial rata-rat dalam satu keluarga memiliki 2 s/d 3 orang anak.

\section{Kondisi Pendidikan}

Kondisi pendidikan di Desa Bunar yang mengenyam pendidikan hingga Perguruan Tinggi sangatlah minim. Karena kurangnya kesadaran akan pentingnya pendidikan dikalangan masyarakat Desa sehingga secara tidak langsung berdampak pada tingkat jenis pekerjaan masyarakat teresebut. [2]

Tabel 2: Jenis Pekerjaan Masyarakat

\begin{tabular}{|c|l|r|r|r|}
\hline $\begin{array}{l}\mathrm{N} \\
\text { o }\end{array}$ & Jenis Pekerjaan & $\mathrm{L}$ & $\mathrm{P}$ & $\mathrm{Jml}$ \\
\hline 1. & Petani & 288 & 288 & 576 \\
\hline 2. & Buruh Tani & 206 & 206 & 412 \\
\hline 3. & PNS & 33 & 23 & 56 \\
\hline 4. & Peternak & 1 & 0 & 1 \\
\hline 5. & Dokter swasta & 0 & 1 & 1 \\
\hline 6. & Perawat swasta & 1 & 2 & 3 \\
\hline 7. & TNI & 5 & 0 & 5 \\
\hline 8. & POLRI & 6 & 1 & 7 \\
\hline 9. & Guru swasta & 18 & 13 & 31 \\
\hline 10. & Pedagang Kel. & 88 & 3 & 91 \\
\hline 11 & Karyawan & 415 & 57 & 472 \\
\hline
\end{tabular}




\begin{tabular}{|c|c|c|c|c|}
\hline & $\begin{array}{l}\text { Perusahaan } \\
\text { swasta }\end{array}$ & & & \\
\hline 12. & $\begin{array}{l}\text { Karyawan } \\
\text { Perusahaan } \\
\text { Pemerintah }\end{array}$ & 1 & 1 & 2 \\
\hline 13. & Wiraswasta & 606 & 9 & 615 \\
\hline 14. & $\begin{array}{l}\text { Tidak } \\
\text { Mempunyai } \\
\text { Pekerjaan } \\
\text { Tetap }\end{array}$ & 383 & 321 & 704 \\
\hline 15. & Belum Bekerja & 622 & 504 & 1126 \\
\hline 16. & Pelajar & 877 & 775 & 1652 \\
\hline 17. & $\begin{array}{l}\text { Ibu Rumah } \\
\text { Tangga }\end{array}$ & 4 & 1643 & 1647 \\
\hline 18. & Pensiunan & 21 & 1 & 22 \\
\hline 19. & $\begin{array}{l}\text { Perangkat } \\
\text { Desa }\end{array}$ & 1 & 0 & 1 \\
\hline 20. & $\begin{array}{l}\text { Buruh Harian } \\
\text { Lepas }\end{array}$ & 680 & 11 & 691 \\
\hline 21 & $\begin{array}{l}\text { Pemilik usaha } \\
\text { jasa trasfortasi } \\
\text { dan } \\
\text { perhubungan }\end{array}$ & 5 & 0 & 5 \\
\hline 22. & Sopir & 110 & 0 & 110 \\
\hline 23. & $\begin{array}{l}\text { Karyawan } \\
\text { Honorer }\end{array}$ & 1 & 0 & 1 \\
\hline 24. & $\begin{array}{l}\text { Pemuka } \\
\text { Agama }\end{array}$ & 3 & 0 & 3 \\
\hline & Jumlah & 4375 & 3859 & 8234 \\
\hline
\end{tabular}

\section{Kodisi Keagamaan}

Masyarakat di Desa Bunar, Kecamatan Cigudeg mayoritas beragama

\section{METODE PENGABDIAN}

Pengabdian dilaksanakan di Desa purasari, Kecamatan Leuwiliang, Kabupaten Bogor yang berjarak \pm 38 Kilometer atau sekitar 2 jam perjalanan darat dari Universitas Ibn Khaldun Bogor. Kegiatan KKN yang dilakukan oleh kelompok mahasiswa merupakan salah satu upaya untuk menerapkan hasil pembelajaran di perguruan tinggi kepada
Islam, sering diadakan majelis ta'alim bersifat mingguan baik untuk ibu-ibu dan bapak-bapak, ketika menghadapi hari besar Islam warga antusian dalam menyambutnya seperti : Tahun baru Islam warga mengadakan istigosah dan pawai obor, Penduduk Desa Bunar mayoritas beragama Islam terlihat dari kehidupan sehari-hari berbagai kegiatan keagamaan yang di selenggarakan dari tempat beribadah, seperti Masjid, Musholla, Pondok Pesantren. [3]

\section{Sarana Dan Prasarana}

Desa Bunar memiliki sarana dan prasarana yang cukup lengkap, berikut ini adalah data-data mengenai sarana dan prasarana yang ada di desa Bunar, yaitu:

Tabel 3 :Data Sarana dan Prasarana.

\begin{tabular}{|l|l|c|}
\hline No & \multicolumn{1}{|c|}{ Jenis Prasarana } & Unit \\
\hline 1. & Puskesmas & 1 \\
\hline 2. & Balai Pengobatan & 1 \\
\hline 3. & Posyandu & 9 \\
\hline 4. & Gedung SMA & 3 \\
\hline 5. & Gedung SMP & 3 \\
\hline 6. & Gedung SD & 5 \\
\hline 7. & Masjid & 6 \\
\hline 8. & Surau/Mushallah & 8 \\
\hline 9. & Karang Taruna & 1 \\
\hline 10. & Bak Sampah (TPS) & 1 \\
\hline
\end{tabular}

masyarakat, karena sebelum mahasiswa menerapkan ilmunya ke ruang lingkup masyarakat perlu dilakukan. Penelitian untuk menemukan permasalahan yang sedang terjadi selama KKN dan penemuan solusi baik jangka panjang maupun jangka pendek. Adapun metode-metode yang digunakan sebagai suatu solusi permasalahan yang ada adalah metode 
Studi Kasus sebagai langkah awal dalam pendekatan keilmuan yang akan diterapkan di masyarakat, metode metode $3 R$ (Reduce, Reuse, Recycle) yang diterapkan untuk program pengurangan sampah sebagai program utama kelompok KKN 53 dan 54, dan Metode Discovery untuk penerapan program pendidikan kepada anak-anak.

\section{Studi Kasus}

Studi kasus merupakan salah satu metode penelitian yang bertujuan untuk mempelajari tingkah laku dari peristiwa yang terjadi, perkembangan maupun keadaan yang sedang, dan telah terjadi di suatu lingkungan, yang melibatkan komunikasi secara individu, masyaraka secara sosial, kelompok maupun sebuah lembaga pemerintahan dan non pemerintahan.

Membutuhkan kondisi yang dilakukan secara alami dan dialami langsung oleh peneliti agar dapat memperoleh informasi yang real terutama di lingkugan masyarakat. Berikut merupakan tahapan yang dilakukan sebagai persiapan sebelum melaksanakan kegiatan:

a. Wawancara, adalah percakapan yang dilakukan antara dua orang atau lebih yang menghasilkan suatu informasi. Dengan memberikan pertanyaan dan mendapatkan jawaban dari sumber yang diwawancarai agar jawaban dapat dimanfaatkan untuk analisis masalah yang terjadi dari sudut pandang sumber yang diwawancarai. b. Metode observasi, adalah teknik pengumpulan data yang didapatkan dari pengamatan terhadap objekobjek alam yang ada.

c. Survei lapangan, merupakan metode yang digunakan untuk melihat langsung lokasi sasaran agar kegiatan sesuai dengan sumber daya yang ada.

d. Metode dokumentasi, proses pencarian data berdasarkan data yang berupa profil desa, catatan, legenda, notulen rapat, dan sebagainya.

\section{Metode 3R (Reduce, Reuse, Recycle)}

3R atau Reuse, Reduce, dan Recycle sampai sekarang masih menjadi cara terbaik dalam mengelola dan menangani sampah dengan berbagai permasalahannya. Penerapan sistem 3R atau reuse, reduce, dan recycle menjadi salah satu solusi pengelolaan sampah dapat dilaksanakan oleh setiap orang dalam kegiatan seharihari.

Reuse berarti menggunakan kembali sampah yang masih dapat digunakan untuk fungsi yang sama ataupun fungsi lainnya. Reduce berarti mengurangi segala sesuatu yang mengakibatkan sampah. Dan Recycle berarti mengolah kembali (daur ulang) sampah menjadi barang atau produk baru yang bermanfaat.[1]

Tahapan dalam pengelolaan sampah dalam pelaksanaanya memiliki beberapa tahapan: pertama membuat Bak penampungan sampah (TPS). Kedua pengadaan Bank sampah. Ketiga Pengelolaan sampah plastik menjadi paving block.

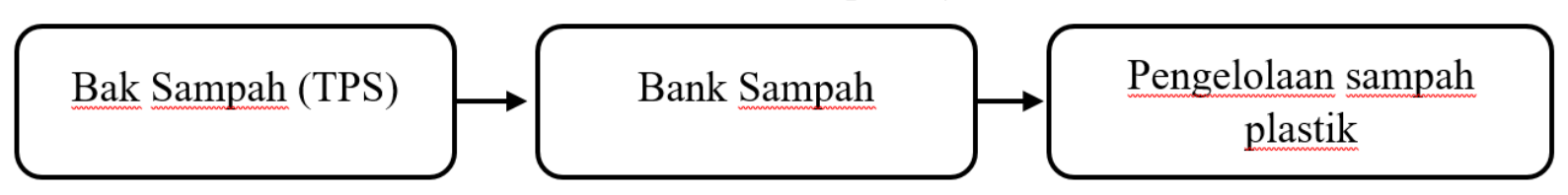

Gambar 2: Diagram tahapan dalam pengelolaan sampah 
1. Analisis situasi Dusun Bunar termasuk dalam kategori pada $t$ penduduka dengan kondisi rumah yang saling berdekatan sehingga hanya ada satu akses jalan untuk lewat satu motor saja. Akan tetapi kepedulian warga terhadap sampah dibilang minim masih banyak warga yang membuang kesungai, disebabkan minimnya tempat pembuangan sampah sehingga warga kesulitan keteika membuang sampah harus kemana.

2. Rancangan dengan pembuatan Bak Sampah (TPS) dapat mengurangi pembuangan sampah ke sungai. Bank Sampah dapat membantu dalam perekonomian desa, seperti halnya menabung akan tetapi menggunakan sampah anorganik yang sudah dipilih sebelumya dari rumah. Dalam proses pendataan saldo setiap nasabah diberikan buku tabungan, dan untuk pengambilan dengan jangka waktu tertentu.

Pengelolaan sampah plastik menjadi paving block menjadi proses terakhir dalam pengelolaan sampah plastik dengan proses beleburan sampah kemudian dicetak menjadi bentuk paving block, dalam satu paving membutuhkan $2 \mathrm{~kg}$ sampah plastik. Dalam proses ini membutukan alat atau

\section{REALISASI PROGRAM}

Program kerja utama Kuliah Kerja Nyata (KKN) kelompok 53 \& 54 adalah penyediaan fasilitas Pengelolaan sampah plastik di Dusun Bunar Desa Bunar, Kecamatan Cigudeg, Kabupaten Bogor.

Program unggulan merupakan program utama yang diajukan oleh anggota KKN Program unggulan juga didampingi dengan program lain sebagai program kegiatan non tema yang memiliki peran mesin yang memang sebagai proses peleburan.

\section{Metode Discovery learning}

Model discovery learning ini menitikberatkan pada kemampuan mental dan fisik para anak didik yang akan memperkuat semangat dan konsentrasi mereka dalam melakukan kegiatan pembelajaran. Adapun tahapan model discovery learning, terdiri dari observasi untuk menemukan masalah, merumuskan masalah, mengajukan hipotesis, merencanakan pemecahan masalah melalui percobaan atau cara lain, melaksanakan pengamatan dan pengumpulan data, analisis data, dan menarik kesimpulan atas percobaan yang telah dilakukan atau penemuan. Jika siswa dilibatkan secara terus-menerus dalam pembelajaran penemuan, maka siswa akan lebih memahami dan mampu mengembangkan aspek kognitif yang dimilikinya [2]

Mendapatkan informasi dari guru yang memang memerlukan suatu metode yang dapat memberikan kesan dan aktif pada siswa, maka kami mencoba dengan metode Discovery learning dalam kegiatan belajar mengajar. Dalam hal ini siswa akan lebih aktif dan mamapu meningkatkan rasa percanya diri siswa. Sekola yang kami pilih yaitu: SDN 03 Bunar dan SDN Papanggungan.

yang tidak kalah penting dari program unggulan.

\section{Bidang Agama Islam}

\section{a. Berpartisipasi pengajian warga}

Pengajian yang dilaksanakan terbagi menjadi dua yang meliputi pengajian ibuibu dan bapak-bapak.

1) Pengajian rutin bersama ibu-ibu pengajian ini dihadiri oleh anggota KKN 54 (Akhwat), ramaja dan ibu- 
ibu sekitar Rt02/Rw01 yang dilaksannakan pada hari kamis ba'da magrib dilasanakan secara bergilir disetiap rumah Kegiatan ini dilakukan untuk menumbuhkan rasa antusiasme kepada ibu ibu, serta menjalin silaturahmi antara anggota $\mathrm{KKN}$ dengan warga.

2) Pengajian rutin bapak-bapak pengajian ini dihadiri oleh anggota KKN 53 Ikhwan, ramaja dan bapak-bapak yang dilaksannakan pada hari sabtu ba'da magrib dilasanakan di Masjid Al-Ading Dusun Bunar, Kegiatan ini dilakukan untuk menumbuhkan rasa antusiasme kepada warga sekitar serta menjalin silaturahmi antara anggota $\mathrm{KKN}$ dengan warga.

\section{b. Pengajian Anak-anak}

Pengajian Anak-anak dilasanaka pada setiap senin s/d jum'at pukul 14.0015.15 pada kediaman ustadz Badru dengan usia anak dari 5 - 10 tahun, proses kegiatan yang dilakuan hanya membimbing atau membatu dalam pembacaan iqra dan jus amma.

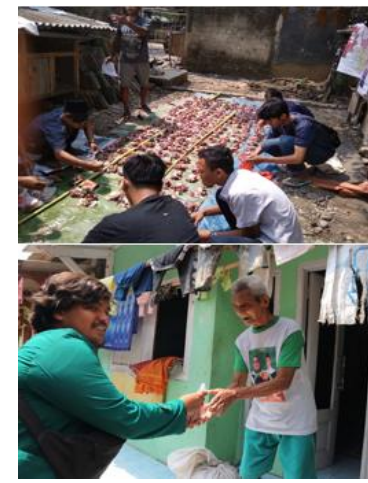

c. Penyelenggara hewan Qurban

Idul Adha terletak pada tanggal 10 Dzulhijjah bias juga disebut "Hari Raya Haji" dimana kaum muslimin menunaikan ibadah hajih yang utama yaitu wukuf Arafah. Seluruh jamaah yang menggunakan palaian serba putih tanpa ada jahitan, dengan melambangkan nilai persamaan dalam setiap segi kehidupan. Dengan satu tujuan yaitu mendekatkan diri kepada Allah yang Maha Perkasa. Dan disamping itu dinamakan "Idul Qurban"

Pada tanggal 11 Agustus 2019 Hari Idul Adha di Indonesia, Dalam kegiatan KKN Tematik Terintregrasi 2019, khusus pada kelompok 53 dan 54 Desa Bunar, Alhamdulillah kita mendapatak donatur berupa 2 ekor kambing yang dinonasikan untuk Dusun Bunar yang terdapat 9 RT dan 18 RT, Dalam kegiatan ini memang pertama kali yang kita lakukan adalah mencari donatur yang ingin berkurban melalui perantara kelompak KKN kami, setelah sosialisasi yang kami lakukan dipekan pertama sebagai bentuk pengenaaln pula mahasiawa UIKA yang menjalankan tugas 30 hari kedepan dari mulai tanggal 6 Agustus, dengan hasil dari sosialisasi kami diberitahukan bahwa dalam pelaksanaan pemotongan hewan qurban terteletak dipinggiran sungai Cidurian, Babakan Asem. Mahasiswa terlibat pula dalam pendataan hewan kurban yang siap di sebelih kurang lebih 30 ekor kambing, dalam pembagian disetiap RW jadi masingmasing mendapakan jatah 3 ekor kambing. Kami juga turut andil dalam persiapan pembagian daging kurban bersama warga setempat. 

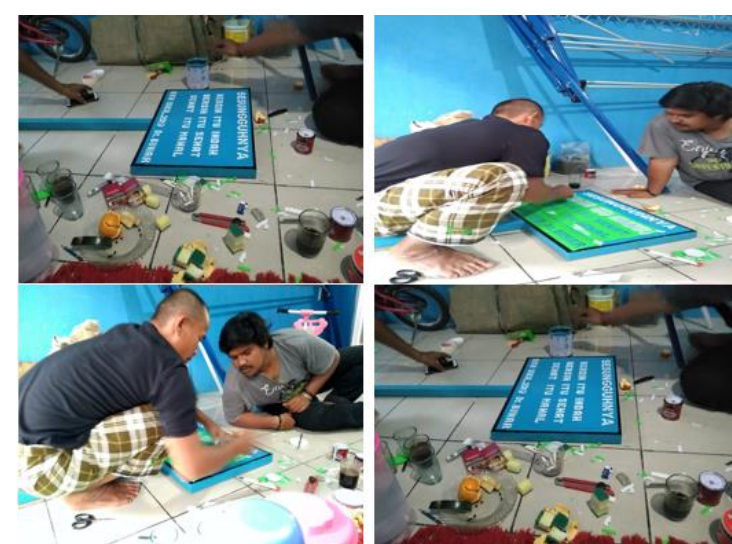

\section{d. Pemasangan Papan jalan Reminder}

Tujuana dari pembuatan plang ini untuk mengiatkan kepada warga untuk selalu menjaga kebersihan lingkungan dengan tidak membuang sampah kesungai mapupun kekebun. Pemasangan plang terletak pada dekat dengan Bak sampah TPS yang kami buat di pinggiran suangai Cidurian, Babakan Asem.

Table 5 : mahasiswa dalam bidang Agama Islam

\begin{tabular}{|c|c|c|c|}
\hline No & $\begin{array}{c}\text { Nama } \\
\text { Mahasisiwa }\end{array}$ & $\begin{array}{l}\mathrm{J} \\
\mathrm{K}\end{array}$ & $\begin{array}{c}\text { Program } \\
\text { Studi }\end{array}$ \\
\hline 1. & $\begin{array}{l}\text { Husein } \\
\text { Taslim }\end{array}$ & $\mathrm{L}$ & Eksyar \\
\hline 2. & $\begin{array}{l}\text { Arrahim } \\
\text { Maulanarrah } \\
\text { man }\end{array}$ & $\mathrm{L}$ & PAI \\
\hline 3. & $\begin{array}{l}\text { Reynaldi } \\
\text { Putra Fradilla }\end{array}$ & $\mathrm{L}$ & PAI \\
\hline 4. & $\begin{array}{l}\text { Magita } \\
\text { Supardi }\end{array}$ & $\mathrm{P}$ & Eksyar \\
\hline 5. & $\begin{array}{l}\text { Qotrunnada } \\
\text { Muthmainnah }\end{array}$ & $\mathrm{P}$ & PAI \\
\hline 6. & $\begin{array}{l}\text { Rizna Dwi } \\
\text { Rahayu }\end{array}$ & $\mathrm{P}$ & PAI \\
\hline 7. & $\begin{array}{l}\text { Siti } \\
\text { Nurjannah }\end{array}$ & $\mathrm{P}$ & PGMI \\
\hline
\end{tabular}

\section{Bidang Kesehatan}
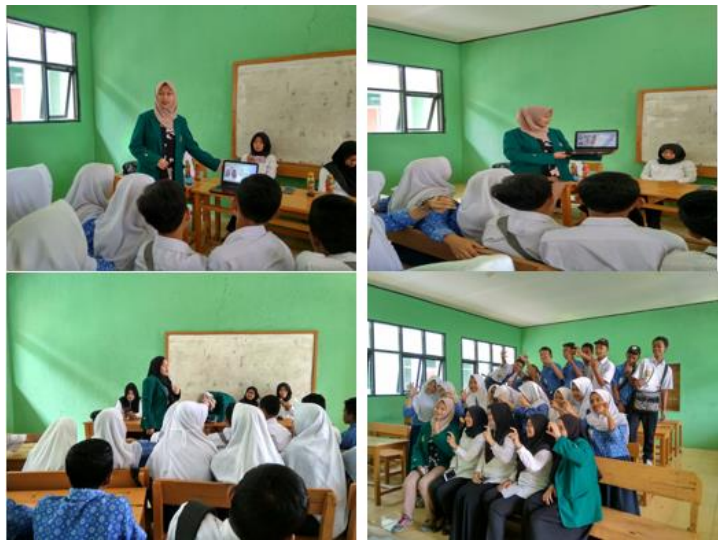

a. penyuluhan dengan tema seks berisiko

Pelaksaa program ini merupakan langkah awal berkerja sama kesehatan masyarakat dengan puskesmas dusun Bunar, dalam kegiatan yang berlangsung pada tanggal 14 agustus 2019 pukul 10.30 WIB bertempat pada SMP BIMA Ds. Bunar, dengan menganalisis kondisi dudun bunar melali survei dan wawancara terkait remaja yang berpacaran sangat tinggi sehingga kami mengambil kesimpulan dengan tema "Sex Beresiko" dengan narasumber mahasiswa fakultas kesehatan.

Tujuan dalam program ini tidak lain adalah untuk mengurangi penderita penyakit kelamin yang sulit diobati dan sangat beresiko. 

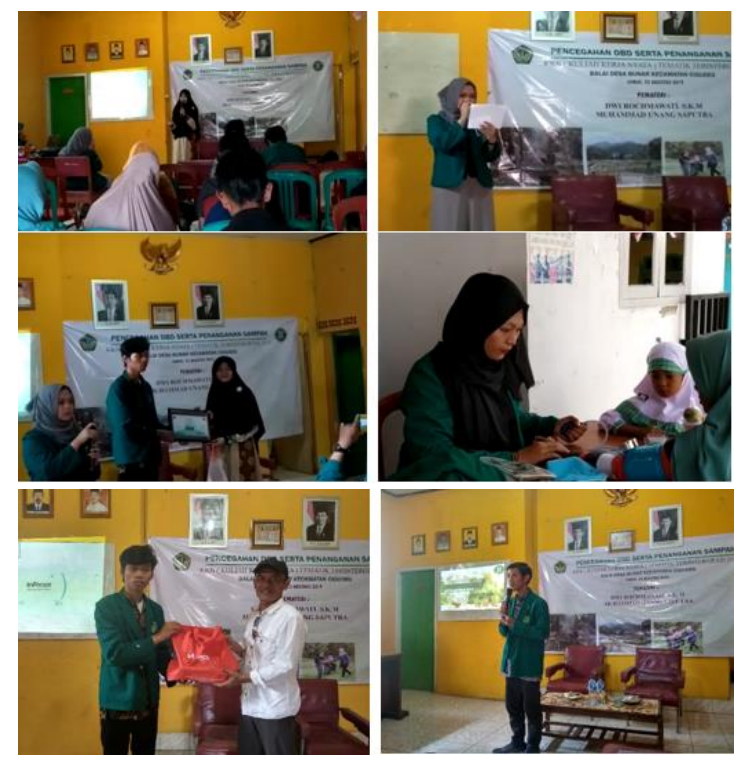

b. Penyuluhan

DBD

dan

Penanggulangan Sampah

Pelaksanaan penyuluhan tentan DBD dan Penanggulangan sampah dengan narasumber lulusan UIKA 2019 Dwi rachmawati S.K.M tetang penyuluhan DBD dan narasumber tentang penaggulangan sampah oleh $\mathrm{M}$. unang Sapura anggota kelompok KKN 5354 menjelaskan pemisahan sampah organik dan anorganik dan pemanfaatan sampah plastik menjadi paving block.

Pelaksanaan program selama 1 hari pada Jumat tgl 23 agustus 2019 bertempat pada Aula kantor Desa Bunar, sekligus kami membuka pengecekan tensi darah gratis, Alhamdullah Tanggapan masyarakat sangat antusias dan mereka mengharapkan agar penanggulangan sampah agar segera dilakukan di desa bunar. Tindak lanjut dari penyuluhan ini adalah pelaksanaan bank sampah dan bak sampah serta penangan sampah dengan sebaik mungkin. Acara ini dihadiri oleh berbagai lapisan masyarakat dari kepala Desa, RW, RT, perwakilan karang taruna desa bunar, Kader Posyandu dan masyarakat, yang dihadiri sampai lebih dari 30 peserta.
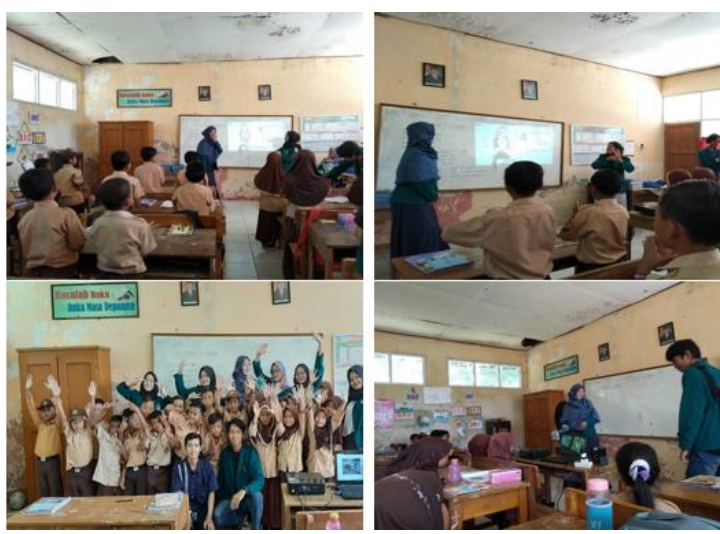

c. Perilaku Hidup Bersih dan Sehat

Pelaksanaanprogram kerja PHBS cuci tangan selasa tanggal 03 September 2019 pukul 09.00 WIB dengan tema 6 langkah cuci tangan di SDN papanggungan desa bunar dengan narasumber mahasiswa Kesehatan.

Dikarenakan semua program dilandasi dengan kebersihan memulai mengenalkan kebersihan dan menjaga lingkunganyang sehat siswa/siswi SD yg sangat berpengaruh akan perilaku hidup bersih dan sehat dilingkungan rumah dan tempat bermain, kelanjutan dari program yang penyuluhan DBD.

Dengan metode Discovery learning yang membuat anak-anak lebih aktif dalam pembelajaran sehingga kami menggunkan musi dan bernyayi lagu 6 langkah cuci tangan.

Table 5 : mahasiswa dalam bidang Kesehatan

\begin{tabular}{|l|l|c|l|}
\hline No & \multicolumn{1}{|c|}{$\begin{array}{c}\text { Nama } \\
\text { Mahasisiwa }\end{array}$} & $\begin{array}{c}\text { J } \\
\mathrm{K}\end{array}$ & \multicolumn{1}{|c|}{$\begin{array}{c}\text { Program } \\
\text { Studi }\end{array}$} \\
\hline 1. & $\begin{array}{l}\text { Dwi } \\
\text { Fatmayanti }\end{array}$ & $\mathrm{P}$ & $\begin{array}{l}\text { Kesehatan } \\
\text { Masyarakat }\end{array}$ \\
\hline 2. & Indah Ardiani & $\mathrm{P}$ & $\begin{array}{l}\text { Kesehatan } \\
\text { Masyarakat }\end{array}$ \\
\hline
\end{tabular}


Bidang Ekonomi

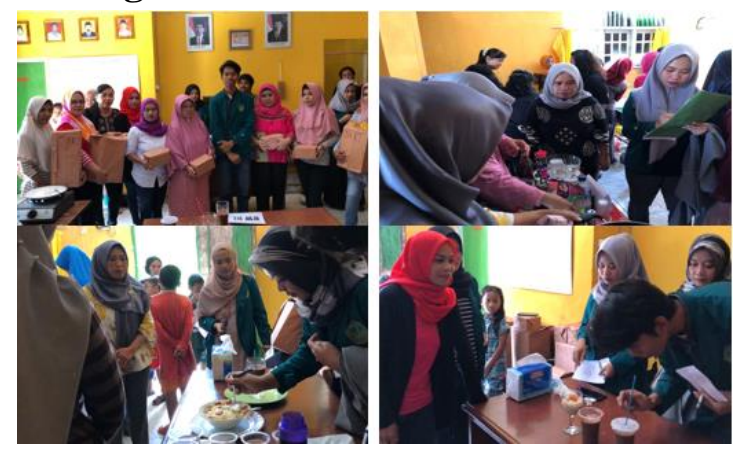

a. Kreativitas Masak Ibu-Ibu Bunar

Sesuai pengamatan dan survei memang mayoritas masyarakat Burar 615 warganya berdagang, sehingga kami mengambil program kerja menambah produk baru dalam berwirausaha sehingga mengambil menu yang baru yaitu salad buah dan pudding sedot, setelah kami survei disetiap Rw pada dusun bunar maka terpilih dua menu tadi, dengan tujuan mengenalkan dan mepraktekan makanan yang sehat sekaligus praktek pembuatan sehingga ibu-ibu mampu membuatnya sendiri dirumah maka menjadi produk rumahan. Waktu pelaksanaan Minggu, 25 Agustus 2019 bertempat pada Aula Kantor Desa Bunar yang dihadiri oleh 9 RW.

Salad buah yang berbahan dasar buah-buahan local memudahkan dalam ibu-ibu dalam mencarinya. Dalam kegiatan ini melibatkan mahasiswa dalam bidang ekonomi sesuai tabel:

Tabel 6 : mahasiswa dalam bidang Ekonomi

\begin{tabular}{|l|l|l|l|}
\hline No & \multicolumn{1}{|c|}{$\begin{array}{c}\text { Nama } \\
\text { Mahasisiwa }\end{array}$} & $\begin{array}{c}\text { J } \\
\text { K }\end{array}$ & Program Studi \\
\hline 1. & Teguh Ismail & L & Management \\
\hline 2. & $\begin{array}{l}\text { Nazarudin } \\
\text { Zulfikri }\end{array}$ & L & Management \\
\hline 3. & Ade Mukhlis & L & Akuntansi \\
\hline 4. & Ayu Ningsihi & $\mathrm{P}$ & Managemet \\
\hline 5. & $\begin{array}{l}\text { Nur Azizah } \\
\text { Luthfah }\end{array}$ & $\mathrm{P}$ & Managemet \\
\hline 6. & Siti & $\mathrm{P}$ & Managemet \\
\hline
\end{tabular}

\begin{tabular}{|l|l|l|l|}
\hline & Krisdayanti & & \\
\hline 7. & $\begin{array}{l}\text { Siti } \\
\text { Nurhalimah }\end{array}$ & $\mathrm{P}$ & Akuntansi \\
\hline
\end{tabular}

\section{Bidang Hukum}

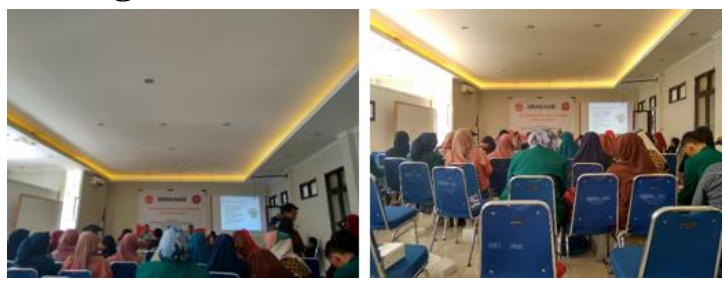

Kuliah

Kerja

Nyata

$(\mathrm{KKN})$

Universitas Ibn Khaldun Bogor menggelar kegiatan seminar yang mengambil judul "Membangun Kesadaran Hukum Terhadap Perlindungan Anak Dan Pemberdayaan Perempuan" yang diadakan di Aula Kantor Kecamatan Cigudeg, Kabupaten Bogor.

Dari pantauan awak media kegiatan seminar kesadaran hukum bagi masyarakat Kecamatan Cigudeg ini begitu ramai dihadiri total 69 orang dari mahasiswa, masyarakat dan tak lupa perwakilan dari Polsek Cigudeg, Sekertaris Camat, Ketua KNPI Kecamatan Cigudeg dan yang tidak kalah hebatnya Narasumber dari team Lembaga Bantuan Hukum (LBH) UIKA dan dari Komisi Perlindungan Anak Indonesia (KPAI).

Lanjut Pemateri Dr. Ibrahim Fajri, S.H Mei dan tim Lembaga Bantuan Hukum Uika Bogor menjelaskan, Anak itu bukan cuma milik orang tuanya tapi juga milik Bangsa karena anak-anak itulah yang akan meneruskan bangsa, jadi harus kita jaga bersama Negara yang maju itu anak di fasilitasi. Ibrahim fajri menyebut banyak perempuan di Indonesia nikah sama orang prancis dia ikut ke prancis karena disana ada tunjangan buat anak dan ibu bahkan ada bantuan untuk pelebaran rumah untuk satu kamar. Ucapnya.

Kekerasan terhadap anak dalam keluarga itu ternyata paling tinggi $91 \%$ dan di sekolah $87 \%$ dan alhamdulilah $\mathrm{LBH}$ 
Uika bekerja sama dengan KPAI Kota untuk bekerja dalam foksi yang sama. Tuturnya.

Pemateri selanjutnya Dudih syiarudin S.sos,MM ( Ketua KPAI (Kota Bogor) menjelaskan dalam acara seminar. Anak di era milenial ini sudah sangat nyambung dengan teknologi modern dan gausah belajar cuma melihat aja sudah pada bisa. Ucapnya.

Table 6 : mahasiswa dalam bidang hukum

\begin{tabular}{|l|c|c|l|}
\hline No & $\begin{array}{c}\text { Nama } \\
\text { Mahasisiwa }\end{array}$ & $\begin{array}{c}\text { J } \\
\text { K }\end{array}$ & \multicolumn{1}{|c|}{$\begin{array}{c}\text { Program } \\
\text { Studi }\end{array}$} \\
\hline 1. & Aldi Maliku & L & $\begin{array}{l}\text { Ilmu } \\
\text { Hukum }\end{array}$ \\
\hline
\end{tabular}

\section{Bidang Pendidiakn}
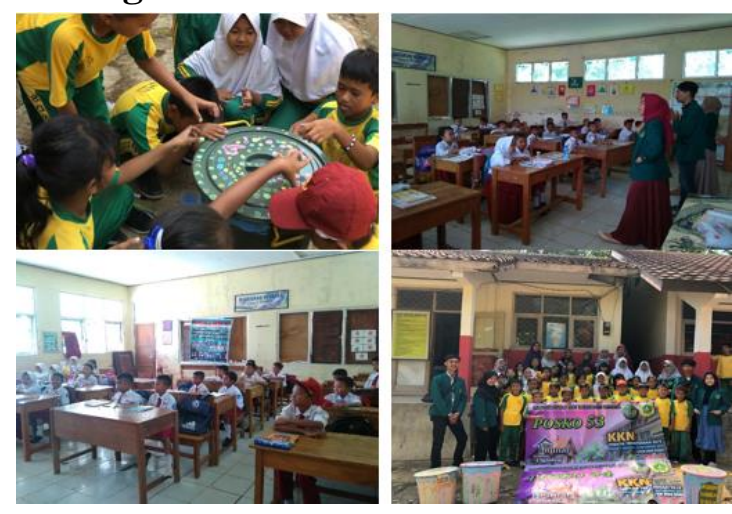

a. Membantu kegiatan mengajar disekolah

Program kerja dalam bidang pendidikan memang membatu pihak seklah dalam kegiatana belajar mengajar tapi tidak hanya mengajar akan tetapi kita juga bergai pengalaman dalam metode pendidikan, memang banyak sekali metode dalam belajar dan kami dari $\mathrm{KKN}$ menggunakan metode yang hampir mirip dengan Discovery learning. Model discovery learning ini menitikberatkan pada kemampuan mental dan fisik para anak didik yang akan memperkuat semangat dan konsentrasi mereka dalam melakukan kegiatan pembelajaran.
Pengambilan tempat yang kami pilih ialah SDN 03 Bunar dan SDN Papaggungan, dalam hal ini mahasiswa ditantang ekstra untum menghapi budaya dan prilaku siswa yang beragam. Dalam seminggu mehadiri senin - jumat disetiap sekolahnya.

Table 7 : mahasiswa dalam bidang Pendidikan

\begin{tabular}{|l|l|c|l|}
\hline No & \multicolumn{1}{|c|}{$\begin{array}{c}\text { Nama } \\
\text { Mahasisiwa }\end{array}$} & $\begin{array}{c}\text { J } \\
\text { K }\end{array}$ & \multicolumn{1}{|c|}{$\begin{array}{c}\text { Program } \\
\text { Studi }\end{array}$} \\
\hline 1. & $\begin{array}{l}\text { Muhammad } \\
\text { Fadil Jumami }\end{array}$ & L & PBI \\
\hline 2. & $\begin{array}{l}\text { Anugrah } \\
\text { Maulidan }\end{array}$ & L & TP \\
\hline 3. & Uus & P & PLS \\
\hline 4. & $\begin{array}{l}\text { Endoh } \\
\text { Raudoh }\end{array}$ & P & PBI \\
\hline 5. & $\begin{array}{l}\text { Imadiyah } \\
\text { Mulqi }\end{array}$ & P & PBI \\
\hline
\end{tabular}

\section{Bidang Teknik}
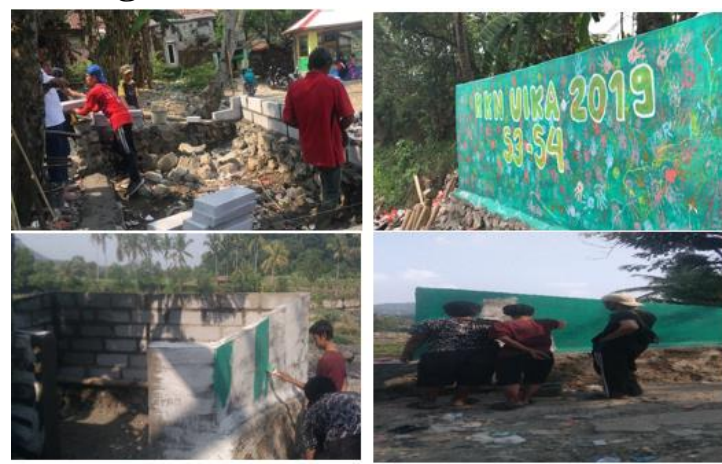

Pengelolaan sampah dengan metode 3R.

Program

kerja

dalam penanggulangan sampah menggunakan metode 3R(Reduce, Reuse, Recycle), dalam penganggulangan sampah kita mempunyai tiga tahapan dalam penaggulanan sampah pada dusun Bunar.

1. Tahapan Pertama adalah pengadaan Bak sampah besar (TPS) Pembuatan TPS bekerja sama dengan seluruh elemen seperti: KKN, Karang taruna, dan warga sekitar, ketua RT, proses 
pembuatan dilukai pada tanggal

Agustus - 2 September 2019.,

terletak di pinggiran sungai Cidurian tidak jaug dari akses jalan raya Cigudeg kurang lebih 50 meter kedalam, dengan ukuran $3 \times 4 \mathrm{~m}$ dengan bangunan permanent sehingga mampu bertahan hingga bertahun-tahun dan tahapan pertama terlaksana.

2. Tahapan kedua pengadaan BANK Sampah minimnya tingkat ekonomi pada dusun Bunar pengadaan Bank sampah sangat efektif jika sudah berjakan dengan baik dan mendapat dukungan dari seluruh warga, sengga pengurangan sampah pelastik dapat berkurang, menambah penghasilan warga maupun ekonomi desa.

\section{"Program ini belum terlaksana"}

Dengan kondisi pengalaman dan informasi kami belum mampu dalam pengadaan secara implementasi terkait bank sampah akan tetapi kami sudah membuat system dan imlemntasi terkait bank sampah. Jika tingkat pembuangan sampah sudah mulai berkurang kesungai maka muncul bank sampah dapat disimpulkan warga sudah mulai peduli dengan sampah

3. Tahap terakhir pengelolaan Sampah dengan jenis plastic menjadi pavingblock, prlaksaan program ini cukup mudah sekali cukum sukan

\section{KESIMPULAN}

Berdasarkan program kerja yang telah dilakukan dengan pelaksanaanya selama satu bulan terhitung dari tanggal 6 Agustus 2019 sampai 5 September 2019, kami mahasiswa KKN Universitas Ibn Khaldun Bogor yang bertempat di Dusun Bunar Desa Bunar Kecamatan Cigudeg Kabupaten Bogor. Kami dapat sampah plastid dilebeur kemudian dicetak dengan cetakan sesuai dengan keinginan. Kami mendapatka informasi dari DPL dan Dosen FTS terkait pengelolaaan sampah plastik. Tahapan terakhir ini menjadi penompoh jika berjalan maka penambahan penghaslian desa. Denga $2 \mathrm{~kg}$ sampah plastic menjadi 1 buah pavingblock dengan harga Rp 5000 dalam sehari mampu menghasilkan $7 \mathrm{~s} / \mathrm{d} 8$ paving. "Program Belum Terlaksana"

Table 8 : mahasiswa dalam bidang Teknik

\begin{tabular}{|c|c|c|c|}
\hline No & $\begin{array}{c}\text { Nama } \\
\text { Mahasisiwa }\end{array}$ & $\begin{array}{l}J \\
K\end{array}$ & $\begin{array}{c}\text { Program } \\
\text { Studi }\end{array}$ \\
\hline 1. & $\begin{array}{l}\text { Asrul } \\
\text { Adriansyah }\end{array}$ & $\mathrm{L}$ & T. Sipil \\
\hline 2. & $\begin{array}{l}\text { Ahmad } \\
\text { Setiawan }\end{array}$ & $\mathrm{L}$ & T. Mesin \\
\hline 3. & $\begin{array}{l}\text { Pri } \\
\text { Rahmantiyo } \\
\text { Ramadhan }\end{array}$ & $\mathrm{L}$ & T.I \\
\hline 4. & $\begin{array}{l}\text { Mohamad } \\
\text { Unang } \\
\text { Saputra }\end{array}$ & $\mathrm{L}$ & T.I \\
\hline 5. & $\begin{array}{l}\text { Yuri Nur } \\
\text { Kholipa }\end{array}$ & $\mathrm{P}$ & T.I \\
\hline 6. & $\begin{array}{l}\text { Muhammad } \\
\text { Musthafa }\end{array}$ & $\mathrm{L}$ & T. Mesin \\
\hline 7. & $\begin{array}{l}\text { Muhammad } \\
\text { Amar Khadafi }\end{array}$ & $\mathrm{L}$ & T. Sipil \\
\hline
\end{tabular}

menyimpulkan bahwa dalam melaksanakan Kuliah Kerja Nyata (KKN) dan merealisasikan berbagai program seperti program bidang pendidikan, kesehatan, ekonomi, agama Islam dan program lainya berjalan dengan baik. Adapun pengalaman dan kondisi lapangan 
yang kami peroleh, dapat kami simpulkan sebagai berikut :

1. Lancarnya Program Kerja yang kita buat merupakan hasil dari kerjasama yang baik antara Masyarakat dengan Mahasiswa. Informasi yang kita dapat dari pihak Desa, Tokoh Masyarakat, dan warga sangat membantu kita selama terlaksananya kegiatan Kuliah Kerja Nyata (KKN).

2. Ilmu yang Mahasiswa punya sangat dibutuhkan oleh masyarakat yang tingkat pendidikan nya masih kurang seperti di Desa Bunar karena faktor ekonomi yang tidak mendukung. Hal tersebut dilihat dari hasil survey, wawancara, dan selama merealisasikan program-program yang ada. Oleh sebab itu, dengan adanya Mahasiswa KKN TT Kelompok 53 dan 54 kita semaksimal mungkin membantu untuk memberikan ilmu dan informasi yang kita punya guna membangun kualitas dan kuantitas hidup masyarakat di Desa Bunar dengan melakukan berbagai penyuluhan dan pengajaran.

3. Akses jalan yang jauh dari perkotaan merupakan hal yang baru ditemui oleh para Mahasiswa KKN TT Kelompok 53 dan 54. Dari kegiatan KKN TT ini mahasiswa jadi bisa ikut berempati atau merasakan bagaimana menjadi warga di desa yang jauh dari kota. Selain itu Mahasiswa juga harus membantu memikirkan solusi-solusi apa yang harus dilakukan untuk memecahkan berbagai permasalahan yang ada di Desa Bunar. Hal tersebut dapat memberikan pembentukan karakter yang baru kepada para Mahasiswa yang harus menjaga tata krama, sopan santun, tutur bahasa dan mengahargai kebiasaan atau budaya yang sudah ada di masyarakat Desa Bunar. Yang demikian bukan hanya semata-mata menjaga nama baik pribadi atau instansi selama kegiatan KKN TT, melainkan membentuk diri menjadi lebih baik setelah selesainya kegiatan KKN TT.

\section{Dampak Bagi Masyarakat}

Selama pelaksanaan KKN kelompok 53 dan 54 di Desa Bunar Kecamatan Cigudeg khususnya di Dusun Bunar memiliki dampak yang signifikan dan dirasakan oleh masyarakat sekitar, yakni semakin terbukanya wawasan dan meningkatnya tingkat kepedulian orang tua dalam menjaga kesehatan, kebersihan khususnya dalam pengelolaan sampah yang memerupakan jadi permasalahan krusial yang dialami masyarakat saat ini. Sehingga terciptanya lingkungan yang bersih sehat, dan kondusif di wilayah Dusun Bunar. Dilihat dari segi pendidikan sendiri, masyarakat terlihat antusias dan terbantu dalam menjalankan program bantuan belajar untuk anak-anak warga Dusun Bunar baik belajar mengaji maupun bimbingan belajar lainya. Kami pun melihat adanya banyak peluang usaha yang dapat dilakukan oleh warga setelah dilakukanya beberapa penyuluhan tentang kewirausahaan seperti demo masak, terbuktinya antusias warga yang tertarik dalam membuat inovasi baru merupakan dampak yang jelas terlihat. 


\section{SARAN}

Berikut beberapa Saran dan yang dapat kami jabarkan selama program KKN TT 2019 yang berlangsung kurang lebih selama 30 hari di Desa Bunar Kecamatan Cigudeg

1. Pemberian dukungan moral ataupun moril yang lebih dari aparat Desa setempat.

\section{DAFTAR PUSTAKA}

Alamendah's Blog, 2010, 3R (Reuse Reduce Recycle) Sampah (online), https://alamendah.org/2010/07/01/3rreuse-reduce-recycle-sampah/, diakses pada 13 September 2019.

"Desa Bunar", diakses pada 4 September 2016 dari laman web: http://kecamatancigudeg.bogorkab.g o.id/index.php/multisite/detail_desa/ 321

"Bunar, Cigudeg, Bogor", diakses pada 4 September 2016 dari: https://id.wikipedia.org/wiki/Bunar, Cigudeg,_Bogor 5

Gina Rosarina, Ali Sudin, Atep Sujana, 2016, penerapan model discovery learning untuk meningkatkan hasil belajar siswa pada materi perubahan wujud benda, UPI Kampus Sumedang.
2. Saling bekerja samanya para pihak terkait, baik Dinas Kepemerintahan, pihak swasta, dan juga kesadaran para masyarakat sendiri.

3. Meneruskan dan menjalankan program kerja yang telah dijalankan atau terealisasi selama kegiatan KKN TT 2019 berlangsung.

I. Sundarta, A. Sari and H. P. Wibowo, "Pengelolaan Limbah Organik Menjadi Kompos melalui Pembuatan Tong Super" Jurnal Pengabdian Pada Masyarakat, 2018.

Prasetya, E. (2018). Pemberdayaan Masyarakat Tentang Kesehatan, Pendidikan dan Kreatifitas. Abdi Dosen: Jurnal Pengabdian Pada Masyarakat 2 (1), 19-25.

Profil Desa Bunar tahun 2015, Dokumen tidak dipublikasikan

Riska Hardiani dan Reza Ayattu Fauzi, 2017. Dedikasi Untuk Desa Bunar, Kelompok ARIES UIN Syarif Hidayatullah Jakarta, Jakarta

Sugiyono. (2005). Memahami penelitian kualitatif. Bandung: ALFABETA. 